\title{
Design of Construction and Controlling of Automation Technics in Order to Improve Skills of Students
}

doi:10.2478/mape-2021-0011

Date of submission to the Editor: 04/2021

Date of acceptance by the Editor: 06/2021

MAPE 2021, volume 4, issue 1, pp. 120-131

\section{Erika Hrušková}

ORCID ID: 0000-0003-4852-7824

Slovak University of Technology, Slovak Republic

\section{Miriam Matúšová}

ORCID ID: 0000-0002-2128-3041

Slovak University of Technology, Slovak Republic

\section{Štefan Václav}

ORCID ID: 0000-0003-3266-3645

Slovak University of Technology, Slovak Republic

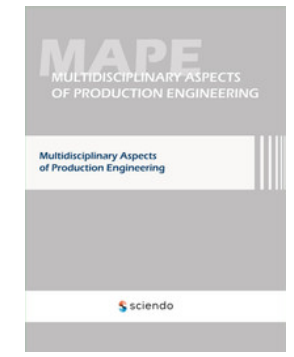

\section{INTRODUCTION}

The didactic principles are sort of requirements, respectively general and specific laws governing teacher teaching activity. Several authors have reported differently formulated various principles in different patterns. All, however, along with selected teaching methods increases the efficiency of the educational process. Didactic principles that are useful to know and apply the undergraduate education include the following:

- Principle of purposefulness,

- Prudent activities

- Principle of scientism and adequate proportionality,

- The principle of combining theory with practice,

- The principle of clarity,

- The principle of consistent and sequence,

- The principle of sustainability knowledge,

- The principle of comprehensive cognitive development of students (Harčarufka et al, 2018).

An important aspect of undergraduate education is the development and shaping of intellectual skills and habits. These allow students to think creatively and independently, creatively and think logically, be able to distinguish between substantial and insubstantial, to know the relationships between them and the context. In terms of teaching principles is the requirement to create in the learning process optimum conditions for connection between theory and practice. Students need to understand how to use theoretical knowledge in practice (Oravcová and Labašová, 2020). Theory and practice form a unity, although each may be prevented. Theoretical training usually precedes the practical application of knowledges, but cannot exclude the opposite procedure. Principle of the connection (practice and knowledge) and next the practice and 
the knowledge verified or rejected. It follows that in the educational process knowledge must never remain at the theoretical level but it must always show their use in practice. This serves a variety of tasks based on the requirements of manufacturing companies that work together to solve them with university.

Robotics is now a modern element of automatic operation and automation is an integral part of the strategies of successful companies (Demeč and Svetlík, 2016). We have to accept this reality and adapt the learning process to new trends, needs and demands of practice for our graduates. For permanent establishment of robotics is necessary to awaken an interest in it already during the course. This required adequate teaching equipment and methodology. Multimedia applications importance is growing in education with the development of Web technology and virtual environments. By utilizing these technologies and using different application software for teaching we achieved a significant increase in the efficiency and attractiveness of individual objects. Implementation of teaching in laboratory using Computes Aided (CA) systems, we meet growing demands of the European labour market as well as the rapidly growing industry in Slovakia, which put employers on graduates of technical universities.

\section{COMPUTER AIDED LABORATORY EDUCATION \\ Computer Aided (CA) Systems and Digital Models}

CA systems are computer systems intended to support activities at all engineering stages - from development and design, production planning, to actual production and assembly, warehousing and shipping. These systems allow accelerate and simplify the particular modelling and drawing, dimensioning, perform analyses design as well as various administrative activities such as archiving, searching and more. They are all modelling software and drawings, the technical computing, simulation and analysis. Using and knowledge of CA systems are commonplace each designer. The continuous training is necessary in this field (Michal et al., 2019), (Václav et al., 2018), (Tvrdon et al., 2015).

Digital product model represents the spatial image. It is a source of information about the actual geometry (shape and position tolerance, the links between dimensions) and the physical and mechanical properties of the product. The digital model is part of the design technology, the analysis and simulations. The entire production process is proposed and simulated based on the obtained models and technologies in systems DF (Digital Factory).

Digital models based CA systems give manufacturers the ability to perform three types of simulations before the start of production of the future product. Namely:

- Geometric (simulation of assembly - inspection of assembly)

- Numeric (strength, thermal and deformation analysis, kinematics tests, etc.)

- Production (production on Numerical Control machines, filling out forms in making plastic parts, etc.). 
The using the CA systems is processed and analysed more and more data and solve problems. These problems are solvable through virtual models. 3D virtual model becomes the basis for the design processes of production systems and also serves the customer first introduction with the product. With these facts in practice will meet current and future university students (Václav et al, 2017), (Gasimov, 2020).

\section{Computer Aided (CA) Systems in Laboratory}

Several CA systems we have available in our CA laboratory. Students solve tasks of varying difficulty using individual software application. Passing training in CA laboratory students acquires skills in creating 3D models. Students create models of components, assemblies, and proposed production system in the CATIA V5 (Václav et al., 2017). The next step is proposed systems design control. The result is a pneumatics electro-pneumatics, hydraulic control circuit. Students determine the proposed control circuit functionality in the simulation environment FluidSim in the next step.

\section{PAD PRINTING METHOD}

The student aim was the design of the automation process for marking wooden hammers. Existing printing machine TC 250 (Fig. 1) is used for the marking wooden hammers.

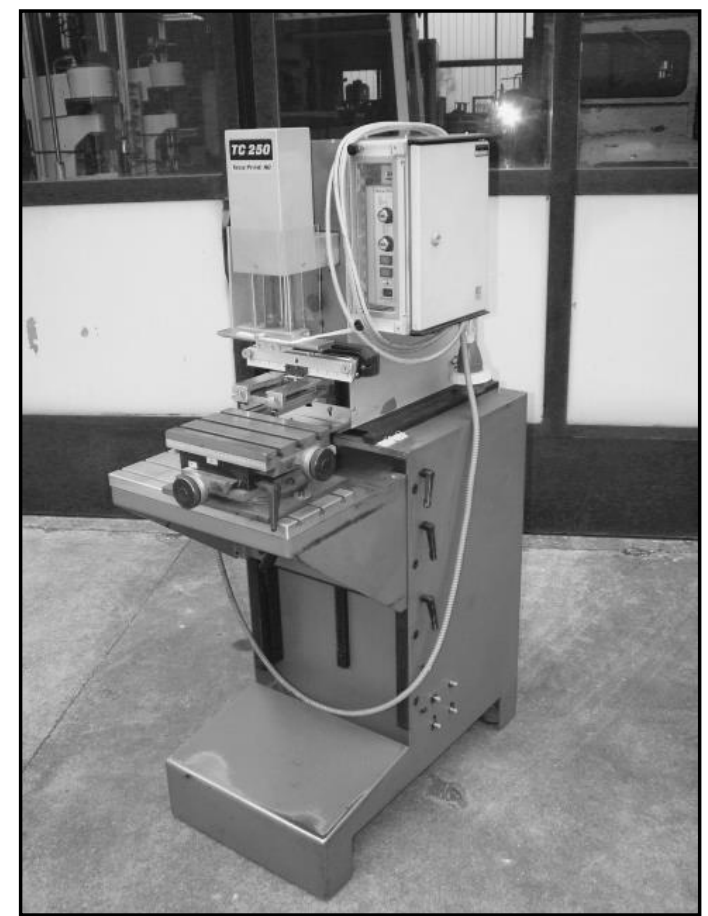

Fig. 1 Printing machine TC 250

The base principle of Pad printing machine is in the colour taking through the pad. The first into a special matrix is etched a print motif. Then the colour is applied to the matrix and it is dull with a sharp sheet. Only the colour in the 
etched part remains. This is then applied to a tampon, a piece of elastic rubber, and a tampon to a suppressed object. Technique is suitable for smaller areas, but thanks to the plasticity of the tampon it is possible to suppress areas that are not equal.

Materials that can be printed: plastics, metal, glass, paper, wood and more. The technology is particularly suited for smaller but more accurate printing.

Table 1 shows the crucial parameters of choose pad printing machine TC 250.

Table 1 Parameters of printing machine TC 250

\begin{tabular}{|c|c|}
\hline Maximum area of printing (d) & $80 \mathrm{~mm}$ \\
\hline Maximum number of colour & 4 \\
\hline Standard format of print & $\begin{array}{c}80 \times 80 \mathrm{~mm}, 250 \times 150 \mathrm{~mm}, 100 \times 80 \mathrm{~mm}, \\
120 \times 120 \mathrm{~mm}, 100 \times 100 \mathrm{~mm}, 250 \times 120 \mathrm{~mm}, \\
130 \times 100 \mathrm{~mm}\end{array}$ \\
\hline Maximum printing speed & 1400 cycles per hour \\
\hline Actuator & pneumatic \\
\hline Operated pressure & $5-6 \mathrm{bar}$ \\
\hline Electricity & $85-265 \mathrm{~V}, 47-63 \mathrm{~Hz}$ \\
\hline Maximum vertical stroke & $100 \mathrm{~mm}$ \\
\hline Area of fixturing table & $450 \times 180 \mathrm{~mm}$ \\
\hline Dimensions without machine support & $471 \times 893 \times 586 \mathrm{~mm}$ \\
\hline Weight without support of machine & $70 \mathrm{~kg}$ \\
\hline Dimensions with machine support & $600 \times 900 \times 1300 \mathrm{~mm}$ \\
\hline Weight with support of machine & aprox 300 kg \\
\hline
\end{tabular}

The wooden carpentry hammers are the subject of printing logos Tornado (Fig. 2).

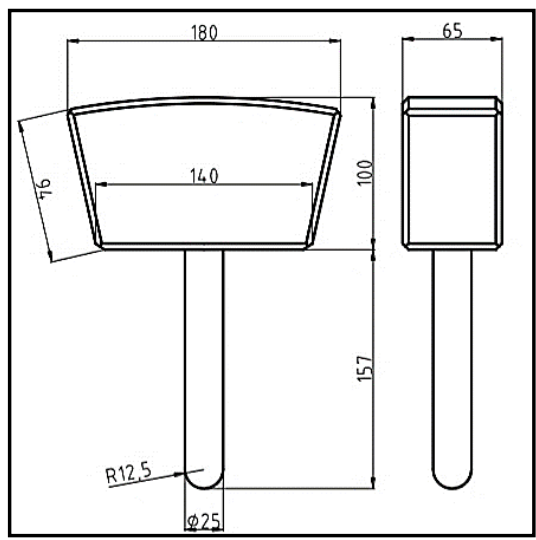

Fig. 2 Wooden carpentry hammer with weight of $1 \mathrm{~kg}$

Pneumatics was used as a means of automation. The principle is the application of printing colour with silicone elastic pad on the subject Fig. 3. Solved labelling process took place with the active participation of the operator. The operator 
had to hammer manually inserted into the working area of the machine for marking workpieces. Then run the machine, after the completion of the hammer had to choose and save it on the technological palette. The production process was considerably slow and insufficiently effective. Automation has improved the safety aspects.

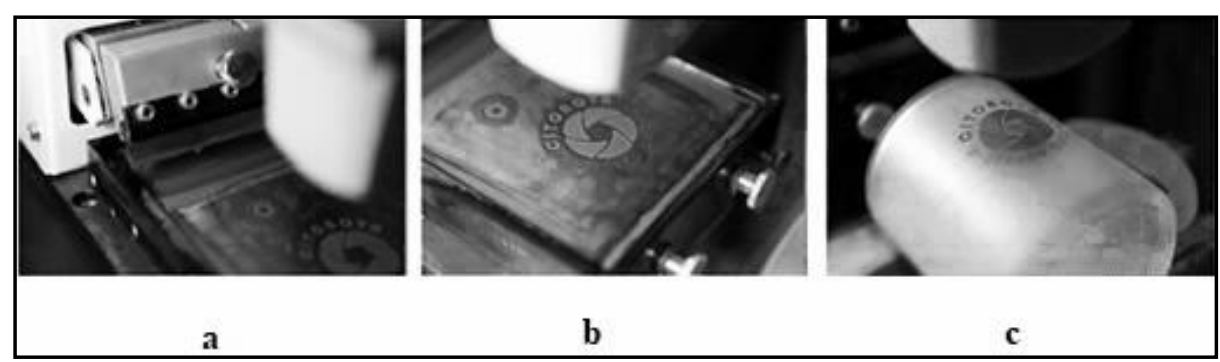

Fig. 3 Pad printing principle:

a - Printing colour is stlathered to cliche where the printed subject is recessed.

The blade wipes away the excess paint.

Residual printing colour is retaining in the recessing.

b - The sillicon pad is moving above the printing desk.

It prints the colour from recessing to its elastic surface.

c - The pad is moving above subject defined to print.

Next it transfers the printed subject from pads surface to printed subject

Printing pads Fig. 4 must have these particularly facilities as high mechanical resistance, stable surface stress, perfectly smooth surface without damages and the pads should be able to take away static charge.

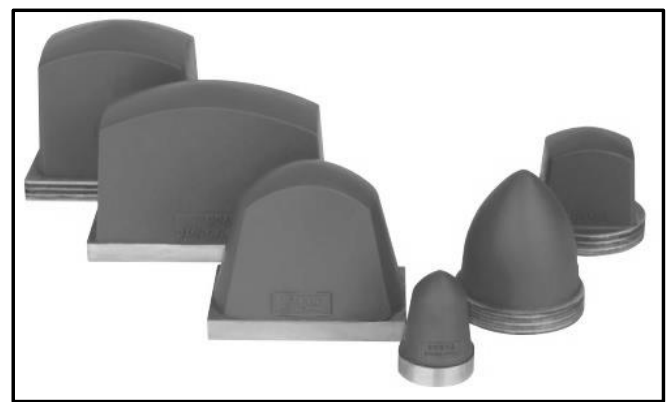

Fig. 4 Pictures of pad types from fy. Teca - print production

Printed subject can be various that is a reason for production of printing pads in several shapes, dimensions and hardness. According to this the pads are most often separate with the colour.

\section{DESIGN AUTOMATION SYSTEM}

The main aim was to create and design automation system for complete printing process included all subsidiary accessories and devices and control circuit too. Next is described each parts of this designed system in details.

Circular rotary table is a major structural component of the proposed system (Fig. 5). Four position and $90^{\circ}$ rotation angle is use of this table. In each position is carried out another operation (Saravanan et al., 2015), (Patil et al., 2018), (Frankovský, P. et al., 2018). Supply hammer on the table and ensure its 
position with the index pins is carried out in the first, the input position. Pad printing takes place in the second position of the rotary table. The certain amount of time without handling the hammer is requires after printing, because drying of wet paint. This provides the third position of the rotary table. Printed hammers removal takes place in the final, fourth position of the table.

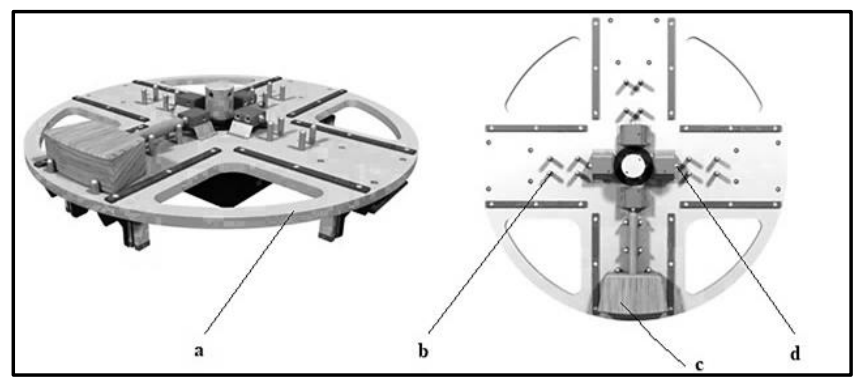

Fig. 5 Rotary table, a - rotary table, b-index pins, c - hammer, $d$ - stopped trips

Hammers are secured to the rotary table and accurately positioned by guide rails; fixed index pins and moving index pins (Fig. 6) in different positions. These elements are modular and can be exchanged. Rotary table can be adapted to another type of product to be applied printing. (Pawar and Taware, 2018), (Singla and Kumar, 2015), (Rahul and Shinde, 2016) Rotary table circular movement is provided by pneumatics rotary driveDHTG-220-4-A from FESTO.

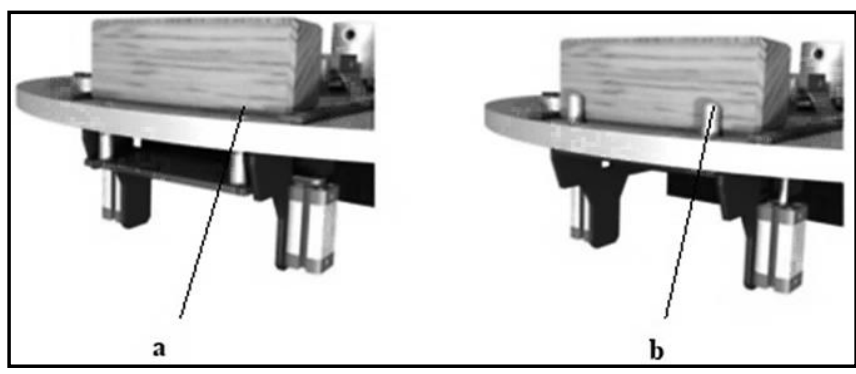

Fig. 6 Hammer fixation without index pins (a) and with index pins (b)

Model proposed facility also includes material flow, the supply and removal of wooden components (Fig. 7, 8). In the guide rails was necessary to resolve the value of friction that come into being in hammer moving and orientation. (Labašová and Labaš, 2018)

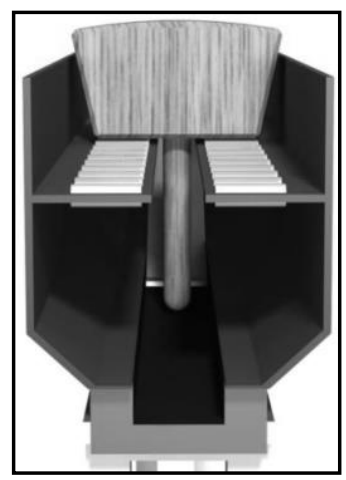

Fig. 7 View of hammer moving in the guide rails 


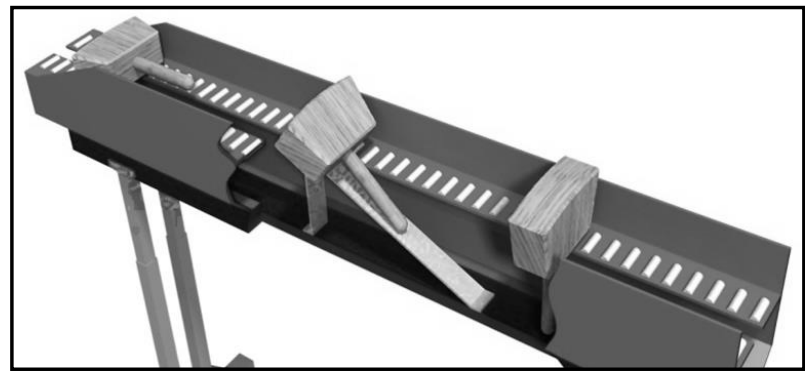

Fig. 8 Hammers change orientation by passive element

The input conveyor is composed of three basic structural elements. There are roller conveyor, rigid passive element of the structure and rotary manipulator. Roller conveyor moves the unmarked hammers to the turntable. Hammers change their orientation through passive element during movement (Fig. 9).

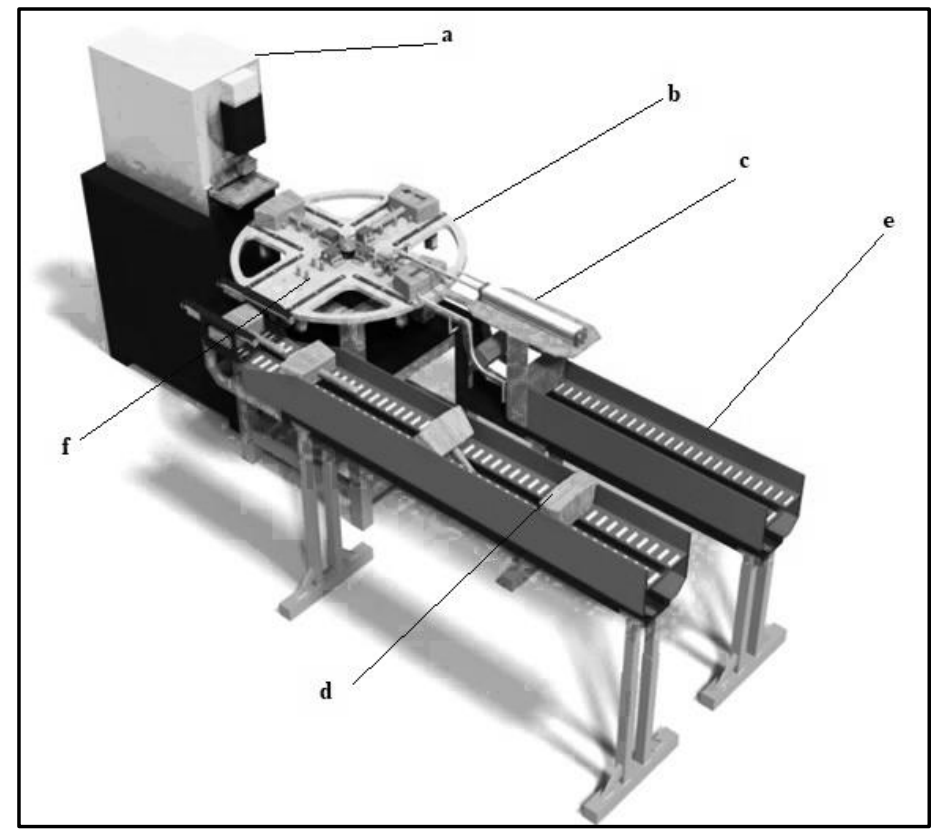

Fig. 9 Designed automated device 3D model

a - printing machine TC $250, b$ - rotory table, c - pneumatic motor, $d$ - hammer, $e$ - conveyor, $f$ - index pins

Hammers movement from the conveyor to position the turntable provides singlepurpose manipulator. Single-purpose manipulator is designed customized workplace for automated labelling of wooden hammers. Removal of hammers is made with standard pneumatic double acting cylinder. The hammer removing from rotary table to the output conveyor is carried three finger gripper. Manipulator is mounted on a simple metal stand which is attached to the output of the roller conveyor (Hlavanda, 2015).

In the first design step were specified all components of the automated equipment (guide rail, jigs, grippers, orientation devices and so on) (Shansevani et al., 2019), (Tarakhovskiy et al., 2017), (Patil and Chinchanikar, 2015). Some components are selected from catalogues and built according to the principle of modularity. Some components are designed and modelled according to the 
requirements. Students in the proposed test their knowledge and skills increase with each CA system.

\section{METHODOLOGY OF RESEARCH VIA CONTROL DESIGN}

The proposed device has been designed electro-pneumatic control system. Individual drives, used in the automated device design are equipped with endpositions sensors. Compilation of the control circuit is preceded by thorough analysis equipment. First we need to check all actuators and sensors. Then assign the sensor signals to positions, which sense. The whole process can be divided into steps. The steps sequence forms a step diagram, with commands, drive movements and signals incurred. Graphics form control algorithm called Grafcet was used (Fig. 10) (Giraldo et al., 2019, Ruiz et al., 2019). Application helped to clarify the algorithm that was divided into individual macro steps. Individual drives were marked as required by the rules for drawing air schemes, namely "A" as the actuator and serial number (Świder, 2015).

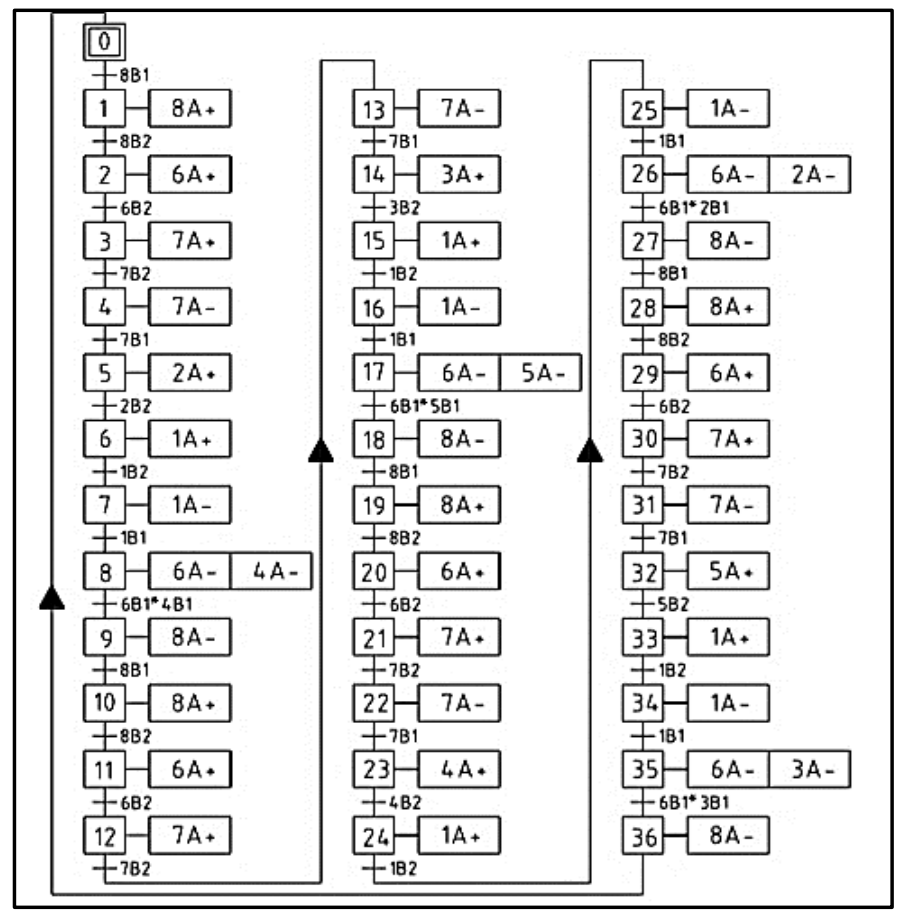

Fig. 10 Control program Grafcet

Software FluidSIM was used as a simulation tool. FluidSIM 4 is comprehensive software for creation, simulation, instruction and study of electro-pneumatic, electro-hydraulic and digital circuits. The simulator uses a range of symbolic and numerical procedures to solve linear, non-linear and differential-algebraic equation systems. Various integration processes are available to the simulator which are selected and controlled intelligently in relation to the operating time (Pauliček et al., 2012). Created simulation of the circuit is illustrating on Fig. 11 and Fig. 12. The control uses the electro-pneumatic circuits. Creation of control circuit is relatively simple and consists of: 
- $\quad$ selection of individual components of hierarchical libraries,

- defining and setting the required values of individual components,

- logic link between different components (Javorova et al., 2012).

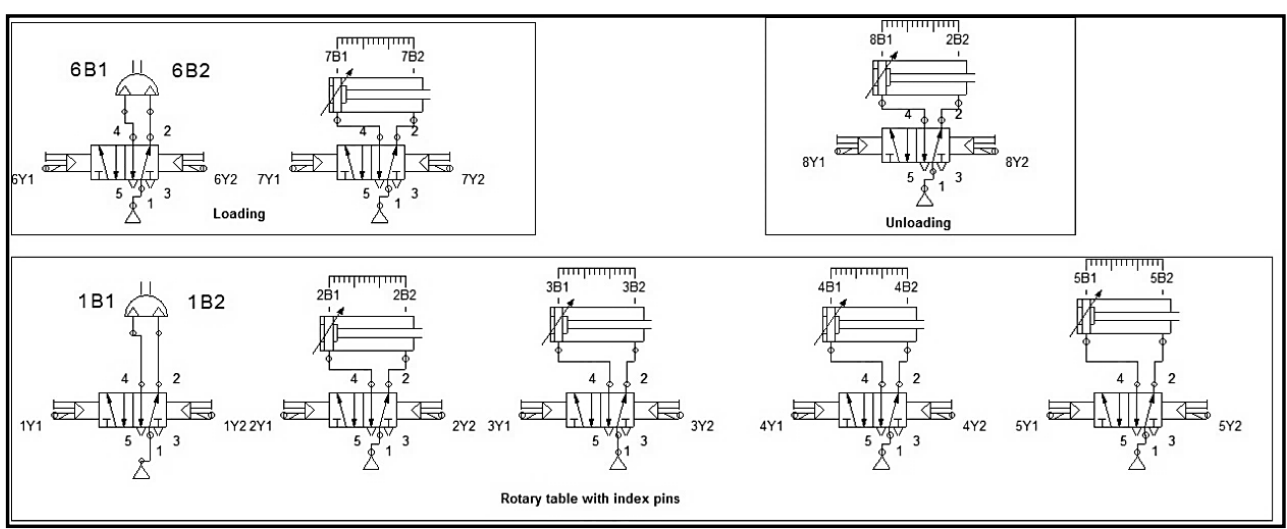

Fig. 11 Pneumatics part of simulation circuit

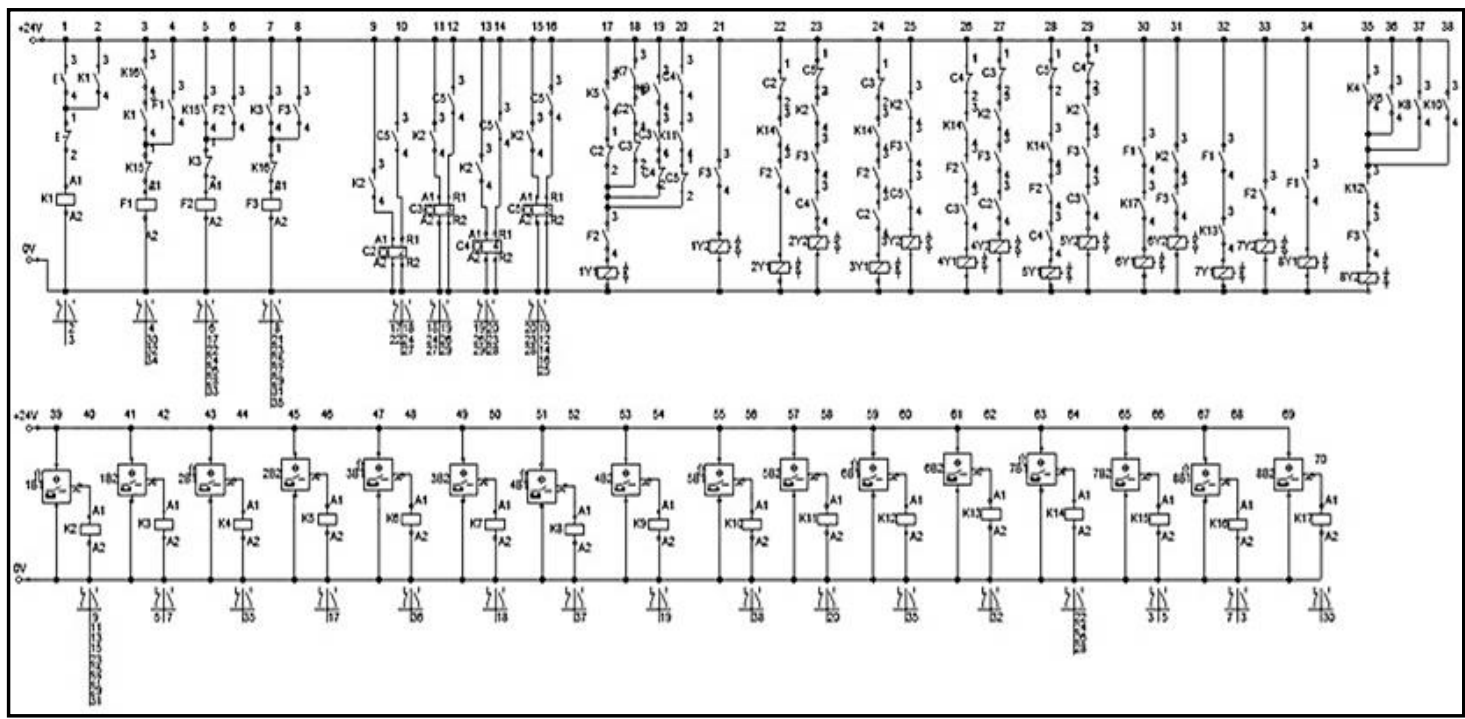

Fig. 12 Electric part of simulation circuit

\section{RESULTS OF RESEARCH}

The aim of designed automation system is work effectivity increasing, increasing of output cycle time and possibility of small modification of assortment thanks to modular fixture elements of rotate table. Simplification of transport system space arrangement of workplace eliminates problems with technological palettes using.

The development of web technology and virtual environments, multimedia applications caused increasing their importance in education. Use of these technologies and using different application software in teaching subjects Industrial robots and manipulators, Programming production and handling technology, Mechanization and automation, we achieved would significantly increase the efficiency and attractiveness of individual subjects (Javorová and Kusá, 2014). 
Knowledge to solve problems with the assistance of CA systems becomes a necessity not only for the student who wants to apply in practice, but also for the teacher, who is supposed to deploy in practice to prepare. Students will gain their knowledges which are by the real firms confirmed and that will be enriched in the future. Effectiveness of learning increases with the number of own students intellectual activity. Currently teaching in a virtual laboratory allows the autonomy, creativity and the own activity of students. It is possible to search and discover new solutions of problems from practice through the CA system using laboratory equipment.

\section{CONCLUSION}

The basis of strategic thinking is just critical thinking, creative thinking, good judgment and good decision-making. Good critical thinking means that we are able to draw the right conclusions much more often. According to Socrates, it is important to look for evidence, examine considerations and assumptions, analyse and look for consequences. This method of proving is a learning strategy of critical thinking. Any software tools, such as CA systems and a GRAFCET step diagram, through the practice examples that really contributes to the development of critical thinking is helpful and at the same time increases students' interest in learning.

\section{ACKNOWLEDGEMENTS}

This contribution was prepared within the framework of the project KEGA 006STU-4/2021: „Progressive form of interdisciplinary education and support for the development of the study of vocational subjects in the university environment".

\section{REFERENCES}

Demeč, P., Svetlík, J., (2016). Production machines. Košice, Publisher: Technical University in Košice, p. 167

Gasimov, H., (2020). „Modelling support systems for selecting professions for applicants in the content of personalization of education." In EUREKA, Physics and Engineering 2020, p. 83-97

Giraldo, J., Duque, J., Forero, J. D., (2019). „Development of a tool for automatic generation of GRAFCET control code using arduino IDE." In International Review of Automatic Control, pp. 210-218

Harčarufka, R., Harčarufkova, K., Perdukova, D., (2018). "Principles for the preparation of educational process" Internet http://www.tuke.sk/ anta/zasady.html, [Mar. 15, 2018]

Hlavanda, P., (2015). "The design of automation process for marking wooden hammers." Graduate Theses, Slovak University of Technology Bratislava. Faculty of Materials Science and Technology in Trnava; Department of Production Systems and Applied Mechanics. Trnava, p. 67

Javorová, A., Kusá, M., (2014). "Robotic system design with CA system support." In Applied Mechanics and Materials: $13^{\text {th }}$ International conference on Industrial, Service and Humanoid Robotics, ROBTEP 2014, Štrbské Pleso, Slovakia, pp. 208-213 
Javorova, A., Oravcova, J., Velisek, K., (2012). "Assemblies system design with modularity and CA support using", In. Proc. Applied Mechanics and Materials, pp. 114-118

Labašová, E., Labaš, V., (2018). "The size of the friction coefficient of the sliding pair depending on the lubricant used." In Novel Trends in Production Devices and Systems IV (NTPDS IV): Special topic volume with invited peer reviewed papers only. Trans Tech Publications, pp. 327-334

Michal, D., Lecký, Š., Košt'ál, P., Václav, Š., (2019). „Welding workstation planning with use of CAD software and simulation. "In Advances in Manufacturing II: Volume 2 - Production Engineering and Management. Cham, Switzerland : Springer Nature Switzerland AG, pp. 97-105

Oravcová, J., Labašová, E., (2020). "Modification of the Sliding Joint in Equipment Tribotestor M'89. "In VELÍŠEK, Karol. Novel Trends in Production Devices and Systems VI. NTPDS VI. Zürich : Trans Tech Publications, p. 296-303

Patil, A., Chinchanikar, S., (2015). „Design and analysis of concrete pipe suspender jaw system using FEA." In International Engineering Research Journal, pp. 20022005

Patil, R., Ambole, N., Awati, S., Shaikh, A., (2018). „A review on lifting and assembly of rotary kiln tyre with shell by flexible gripper." In Journal for Research. pp. 38-40

Pauliček, R., Haluška, T., Važan, P., (2012). "The simulation of the assembling production process". In Proc. Advances in Intelligent Systems and Computing: Proceedings of the Second International Conference on Advances in Computing and Information Technology (ACITY 2012), pp. 273-278

Pawar D., Taware, O., (2018). „Modeling of concrete pipe auto gripping jaw for pipe handling. "In IOSR Journal of Mechanical and Civil Engineering. NCRIME, pp. 62-69

Rahul, P., Shinde, B. M., (2016). „Design and analysis of rotary kiln tyre rigging system using FEA. "International Enginnering Research Journal. MECH PGCON, pp. 768-775

Ruiz, P. V., Fontanini, P. S. P., Correa, F. R., (2019). „Materials flow investigation: An aluminum frames supply chain simulation." In International Review on Modelling and Simulations, pp. 30-36

Saravanan, B., Jeevanandham, M. R., Nirmal, S., (2015). „Design of twin rod assembly using inventor. "In International journal of scientific progress and research, pp. 43-47

Shansevani, R., Reitelshofer, S., Bodaghi, M. A., Franke, J., (2019). „Development of new extensible components for enabling a more flexible usage of jamminggripper."In IEEE International conference on robotics and bioimimetics - Robio 2019. Piscataway: IEEE, pp. 196-202

Singla, R., Kumar, S., (2015). „An intelligent clamping system for drilling operation - a review. "In SSRG International Journal of Mechanical Engineering, p. 39- 42

Świder, J., (2015). Control and automation of technological processes and mechatronic systems. Pneumatics and electropneumatic systems with logic control (PLC).Wydawnictwo Politechniki Ślaskiej, Gliwice

Tarakhovskiy, A., Bukach, B., Tabakaev, D., (2017). „Mechanical Device for Sealing Ring Mounting into Internal Groove and its Opening Technical and Economic Justification. In International Cnference on Industrial Engineering (ICIE 2017), vol. 206, pp. 1438-1442

Tvrdon, L., Juraskova, K., (2015). „Teaching simulation in logistics by using Witness and Captivate software." In: International konference on new horizons in education, INTE 2014, Paris, pp. 4083-4089

Václav, Š., Jurko, J., Lecký, Š., (2017). "Allowance treatment static designed couple and repeatable precision in assembly". In MATEC Web of Conferences. Vol. 137, Modern Technologies in Manufacturing (MTeM 2017 - AMaTUC), Cluj-Napoca 
Václav, Š., Koštál, P., Lecký, Michal, D., Bako, B., (2018). „Assembly system planning in automotive industry with use of discrete event simulation." In Vehicle and Automotive Engineering 2: proceedings of the $2^{\text {nd }}$ VAE 2018, Miškolc, Hungary. 1. vyd. Cham: Springer, pp. 503-515

Václav, Š., Koštál, P., Lecký, Ś., Michal, D., (2017). "Influence of selected attributes in assembly systems planning with use of simulation software. In Industry 4.0, In. Proc. International Scientific Conference, 1. eddition: Scientific-technical Union of Mechanical Engineering Industry 4.0, 13-16.12.2017, Borovets, Bulgaria, pp. 1567

Frankovský, P., Pástor, M., Dominik, L., Kicko, M., Trebuňa, P., Hroncová, D., Kelemen, M. (2018, May). Wheeled mobile robot in structured environment. In 2018 ELEKTRO (pp. 1-5). IEEE.

\begin{abstract}
The article summarizes the experience, skills of the students of technical subjects teaching methodologies using a number of software products. Solve specific assigned tasks described in this paper. Task is about the problems of automation and mechanization in the industry. That helps to improve the skills of praxis, through the design of construction and of controlling. Specifically it focuses on introducing automation in the wood industry. Article describes the design of the automation process for marking wooden hammers. Similar problems are solved by students in Computer Aided (CA) systems. The control process of automation is realized through the electro-pneumatic circuits. These circuits are creating in software FluidSIM 4 that is used as a simulation tool. FluidSIM 4 is comprehensive software for creation, simulation, instruction and study of electro-pneumatic, electro-hydraulic and digital circuits.
\end{abstract}

Keywords: CA system, Education, Simulation, Subject, Construction 